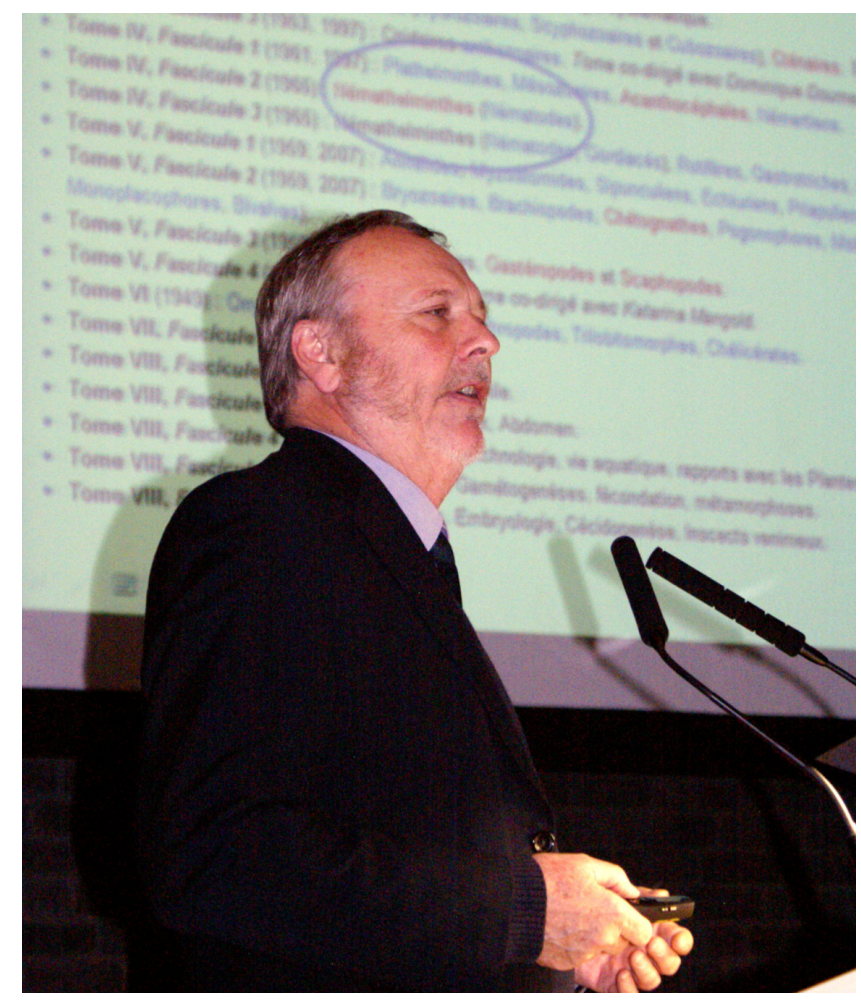

\title{
Carlo Heip (1945-2013)
}

Carlo Heip (1945-2013) studied biology at Ghent University, where he graduated with a study of the ecology and population dynamics of meiobenthos. His study site was a small brackish-water pond but his interest was the ocean and his peers were international colleagues. He founded a research team on marine biology at Ghent University that still exists. The team became integrated in the first Belgian multidisciplinary oceanographic project in the mid1970s. At this time he wrote a seminal paper on the ecology of marine nematodes, focusing on the functional role and ecophysiology of meiobenthos, explored ecotoxicology of metals in nematodes, and developed the use of meiobenthic diversity as a tool in biomonitoring. As the chairman of ICES's benthic ecology working group, in 1986 he organized the North Sea Benthos Survey, one of his first big international achievements.
When he became director of the Delta Institute of Hydrobiological Research in Yerseke, the Netherlands in 1987, the institute was looking for a new identity. It had been founded to ensure scientific follow-up of the Delta Works that closed off the major estuaries in the SW Netherlands. After completion of the works the institute was reoriented, under Heip's guidance, to play an international role in the study of the ecology of estuaries and coastal seas. Around 1990 he coordinated the EU project JEEP92, which compared and modelled the ecology of several European estuaries. In 1992 the Delta Institute became part of the Netherlands Institute of Ecology (NIOO-KNAW). On this occasion Heip founded and led a research group that focused on the interaction between species and their biogeochemical and physical environment. The research had a strong modelling component and stretched from estuaries to the 
deep sea. It resulted in a few well-known reviews on estuarine processes, new model developments especially for benthic processes, and the development of new biogeochemical methods, in particular using stable isotopes, for the study of estuarine ecology. In contrast to most studies in biogeochemistry, it kept a strong focus on biology and species.

From the early 1990s onwards, he was very active as a PI and co-ordinator of European research projects in land-ocean interaction studies. He was the driving force behind the ELOISE initiative, which succeeded in bringing together many excellent research projects in coastal ecology.

Within the scientific study of global change, he had the strong feeling that biodiversity issues were underrepresented, at least in part because the specialists on marine biodiversity were split into many isolated groups with few ties to ecology. For this reason he actively engaged in several initiatives to bring together the relevant partners. This resulted in initiatives such as the marine research stations network (MARS) and, very importantly, the European Network of Excellence MARBEF (Marine Biodiversity and Ecosystem Function). MARBEF resulted in many excellent studies on marine biodiversity and also in compiled datasets at European scale. It greatly contributed to international biodiversity databases such as OBIS (Ocean Biodiversity Information System) and to global initiatives such as the Census of Marine Life. Most importantly, it succeeded in organizing the community and representing biodiversity scholars in multidisciplinary marine initiatives, as well as representing marine biodiversity in the overall biodiversity organisations.

In 2006, Heip became director of the Netherlands Institute of Sea Research (NIOZ) at Texel. He remained there until his retirement in 2011. As a director he managed to lead the institute to achieve a high level of recognition in 2011. He also achieved the merging of the NIOO-CEME in Yerseke with NIOZ, thus bringing together the two Dutch institutions to which he had devoted his professional life. Between 1993 and 2010 he acted as scientific editor of Scientia Marina.

After his retirement he continued representing marine biodiversity in many global platforms. He became editor-in-chief of the Journal of Sea Research and had many plans. These were severely shortcut by the illness that struck him in the autumn of 2012 .

Heip had the leadership and vision that made him an excellent organizer, both as a director and as a co-ordinator of the numerous international initiatives he was involved with. His sharp intelligence and remarkable memory allowed him to participate in a broad scientific field. He had an innovative and creative mind and a special gift for summarizing the essence of a scientific field or debate. He was, above all, a people manager. He had a keen interest in people and knew perfectly well what to expect from them. He stimulated his collaborators by giving them respect, trust and strategic guidance. Even when disagreeing he would always try to understand other people's motives and goals. As a teacher, he stimulated by sketching perspectives more than by prescribing actions.

Already as a teenager, when he was a bird watcher, Heip had a drive for nature. He was keen on bringing scientific knowledge to the policy and management level and on improving coastal and marine management. He was involved with local and regional estuarine management, as well as with $\mathrm{Eu}-$ ropean and worldwide programmes for the protection of biodiversity. And above all, he was a warm person with a good sense of humour, who enjoyed all good things in life.

PETER HERMAN NIOZ Yerseke 